07;09

\title{
Численное моделирование токовой зависимости спектров излучения мощных импульсных лазеров, выполненных на основе двойных гетероструктур раздельного ограничения
}

\author{
(c) А.В. Рожков, Н.А. Пихтин
}

Физико-технический институт им. А.Ф. Иоффе РАН, Санкт-Петербург, Россия

E-mail: rozh@hv.ioffe.rssi.ru

Поступило в Редакцию 16 фревраля 2018 г.

Для описания наблюдаемой токовой зависимости спектров излучения мощных импульсных лазеров на основе двойных гетероструктур раздельного ограничения предложена новая физическая модель, учитывающая наличие на интерфейсной границе волноводных и активной областей изотипных $n-n$-гетеропереходов. Выполнено численное моделирование процессов лазерной генерации. Полученная аналитическая токовая зависимость двумерной концентрации дырок в квантовой яме позволила впервые оценить токовую зависимость коротковолновой границы спектра лазерного излучения. Достигнуто хорошее согласие расчетных и экспериментальных характеристик.

DOI: 10.21883/PJTF.2018.11.46196.17256

При исследовании мощных импульсных полупроводниковых лазеров существенное внимание уделяется не только изучению возможности повышения выходной оптической мощности и установлению условий высокой дифференциальной токовой эффективности, но и вопросам спектральной однородности лазерной стимулированной рекомбинации в широком диапазоне изменения плотности токовой модуляции. Увеличение интенсивности лазерного излучения на основной длине волны стимулированной рекомбинации является актуальной задачей проводимых исследований. Для режимов непрерывной токовой модуляции насыщение интенсивности и длинноволновый сдвиг спектра излучения связаны с ростом температуры лазерного кристалла при 
уровне плотностей тока накачки $J>20 J_{t h}=2 \mathrm{kA} / \mathrm{cm}^{2}$ [1]. В работе [2] показано, что в импульсных режимах наблюдаемый эффект насыщения интенсивности на основной длине волны излучения и расширения спектра в коротковолновую область имеет иную физическую причину, так как при длительности импульса $\tau \leqslant 100$ ns и частоте $f \leqslant 1 \mathrm{kHz}$ температура лазерного кристалла составляет менее $50^{\circ} \mathrm{C}$ при плотности тока накачки $J>80 \mathrm{kA} / \mathrm{cm}^{2}$. Для объяснения наблюдаемых экспериментальных зависимостей была предложена физическая модель, учитывающая электрон-фононное взаимодействие [3]. Согласно выполненным расчетам, при фиксированной скорости рассеяния энергии электронов с учетом эффектов накопления неравновесных фононов наблюдается рост температуры электронного газа и двумерной концентрации электронов в квантовой яме $\left(N^{\mathrm{QW}}\right)$. Полученные абсолютные значения $N^{\mathrm{QW}}$ не дали должного соответствия с наблюдаемыми в эксперименте токовыми зависимостями оптической эффективности и коротковолнового сдвига спектра излучения. Исследования в этом направлении были приостановлены. Предложенные варианты оптимизации полупроводниковой гетероструктуры обеспечили подавление процесса делокализации носителей заряда из активной области в волноводные слои для лазеров диапазона излучения $\lambda=1.0-1.1 \mu \mathrm{m}$ [4] и позволили управлять интенсивностью линии спонтанного излучения материала волноводной области. Однако это не привело к росту оптической эффективности на основной длине волны излучения квантово-размерной активной области. Ширина спектра излучения для лазеров с $\lambda=1.02 \mu \mathrm{m}$ достигает $70 \mathrm{~nm}$ при $J=80 \mathrm{kA} / \mathrm{cm}^{2}[2,4]$. Таким образом, использованные подходы к изучению проблемы токовой зависимости оптической эффективности не обеспечили должного понимания природы наблюдаемого явления, что потребовало разработки новой физической модели. В настоящей работе представлены результаты численного моделирования процесса стимулированного лазерного излучения в рамках физической модели, учитывающей наличие на интерфейсной границе волноводных и активной областей изотипных $n-n$-гетеропереходов (рис. 1).

В соответствии с правилами построения зонной энергетической диаграммы гетеропереходов на интерфейсной границе широкозонного и узкозонного материалов в зонной диаграмме наблюдается разрыв зон проводимости и валентной зоны. Разрыв зонной диаграммы в валентной зоне $\Delta E_{V}$ не служит потенциальным барьером для дырок, диффундирующих со стороны $P$-эмиттера. Разрыв зон проводимости

Письма в ЖТФ, 2018, том 44, вып. 11 

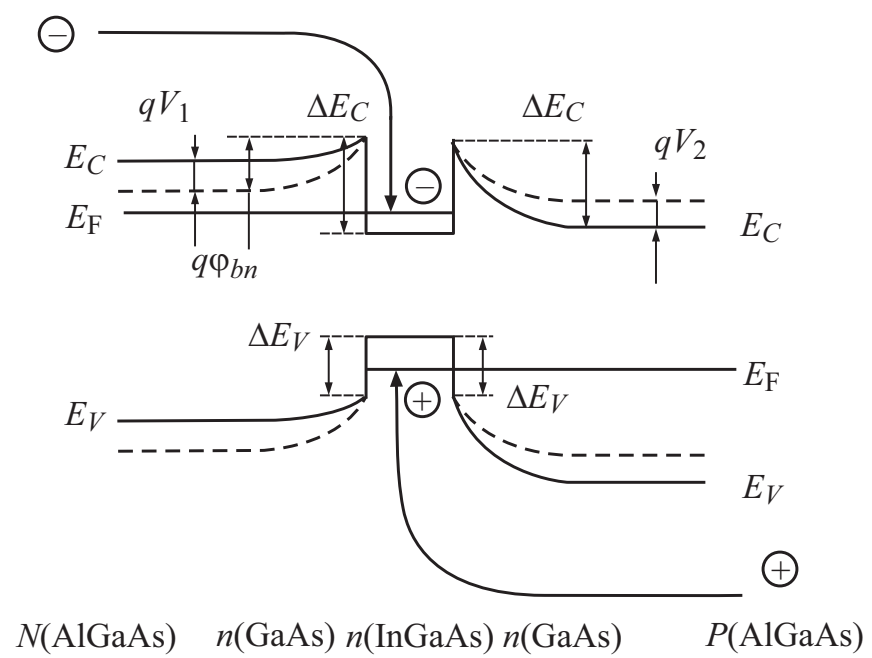

Рис. 1. Зонная энергетическая диаграмма изотипных $n-n$-гетеропереходов импульсного инжекционного лазера на основе двойной гетероструктуры раздельного ограничения. Штриховые кривые - в условиях термодинамического равновесия, сплошные кривые - в условиях протекания тока накачки.

$\Delta E_{C}$ определяет в значительной степени величину потенциального барьера для электронов, диффундирующих от $N$-эмиттера к квантовой яме. Присутствие потенциального барьера для электронов влияет на процесс переноса электронов из волноводной области в квантовую яму. Перенос заряда через изотипный $n-n$-гетеропереход описывается теорией термоэлектронной эмиссии, впервые использованной для случая контакта металл-полупроводник. Согласно этой теории, вольтамперные характеристики изотипных гетеропереходов имеют тот же вид, что и вольт-амперные характеристики $p-n$-переходов, различаются лишь выражения для плотности тока насыщения [5]

$$
J=J_{0}[\exp (q V / k T)-1], \quad J_{0}=q A^{*} T^{2} \varphi_{b n} / k T \cdot \exp \left(-q \varphi_{b n} / k T\right),
$$

где $k$ - постоянная Больцмана, $A^{*}-$ эффективная постоянная Ричардсона для термоэлектронной эмиссии свободных электронов, $\varphi_{b n}-$ высота барьера в условиях термодинамического равновесия.

Письма в ЖТФ, 2018, том 44, вып. 11 
Согласно равенству (1), для лазеров с эффективной глубиной квантовых ям $q \varphi_{b n}=180$ и $130 \mathrm{meV}$ значения плотности тока насыщения составляют 3.9 и $20.8 \mathrm{kA} / \mathrm{cm}^{2}$ соответственно. При расчете тока насыщения использовались значения потенциального барьера на интерфейсной границе с учетом данных работы [6]. Оценки показывают, что токовая эффективность изотипных гетеропереходов более чем в 2 раза выше для лазеров с меньшей эффективной глубиной квантовой ямы. У более эффективных изотипных гетеропереходов протекание фиксированной плотности тока обеспечивается меньшим напряжением смещения.

В предложенной физической модели рассматривается непрямая инжекция неравновесных носителей заряда в квантовую яму. Инжектированные электроны и дырки от эмиттеров $n$ - и $p$-типа проводимости в результате диффузии перемещаются к квантово-размерной активной области. Дырки свободно попадают в квантовую яму, а для преодоления электронами потенциального барьера на интерфейсной границе требуется фиксированный уровень положительного смещения, который обеспечивается в результате накопления положительного заряда со стороны активной области и отрицательного в волноводной области со стороны эмиттера $n$-типа проводимости. Соотношение зарядов дырок и электронов на интерфейсной границе волноводной и активной областей задается параметром $\Theta$. При расчете значения параметра $\Theta$ учитывались экспоненциальный спад концентрации инжектированных носителей от эмиттеров к интерфейсной границе и соотношение времени стимулированной рекомбинации и диффузионного дрейфа носителей заряда к активной области лазерной структуры. Получена зависимость

$$
\Theta=\left(d_{1}^{\mathrm{OCL}} / d_{2}^{\mathrm{OCL}}\right)^{2}\left(L_{p} / L_{n}\right) \exp \left(-d_{2}^{\mathrm{OCL}} / L_{p}\right) / \exp \left(-d_{1}^{\mathrm{OCL}} / L_{n}\right) .
$$

В базовых структурах импульсных инжекционных лазеров расстояния от активной области до эмиттеров $n$ - и $p$-типов проводимости составляют соответственно $d_{1}^{\mathrm{OCL}}<L_{n}$ и $d_{2}^{\mathrm{OCL}}<L_{p}\left(L_{n}, L_{p}-\right.$ диффузионная длина электронов и дырок), что обеспечивает эффективный диффузионный транспорт носителей. Асимметричное положение активной области в сверхшироком волноводе при $d_{1}^{\mathrm{OCL}}(1.3 \mu \mathrm{m})$ и $d_{2}^{\mathrm{OCL}}(0.4 \mu \mathrm{m})$ обеспечивается в соответствии с неравенством $\Gamma_{0}^{\mathrm{QW}} / \Gamma_{m}^{\mathrm{QW}}>1.7$, где $\Gamma_{0}^{Q W}$ и $\Gamma_{m}^{\mathrm{QW}}-$ факторы оптического ограничения для нулевой моды и моды $m(m=1,2,3, \ldots)[1]$. При фоновом уровне легирования волноводных

4 Письма в ЖТФ, 2018, том 44, вып. 11 


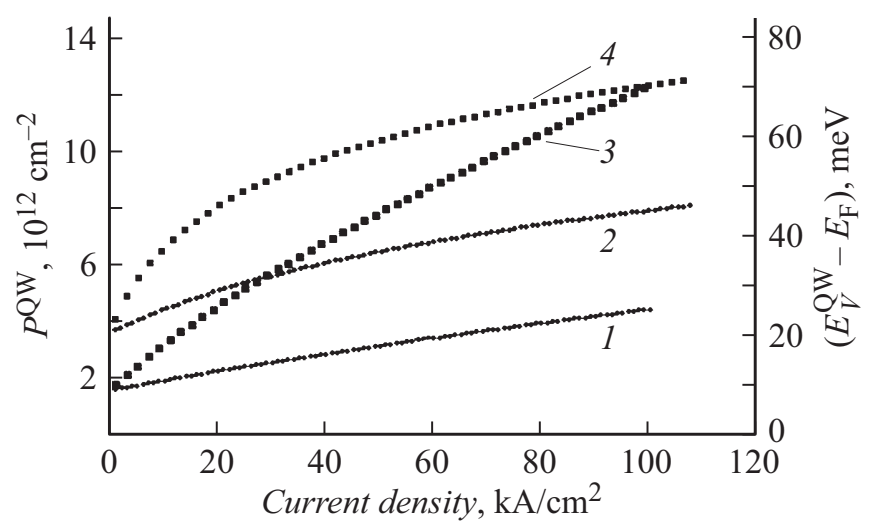

Рис. 2. Результаты численного моделирования токовой зависимости двумерной концентрации дырок в квантовой яме $P^{\mathrm{QW}}(1,3)$ и положения уровня Ферми относительно дна валентной зоны квантовой ямы $\left(E_{V}^{\mathrm{QW}}-E_{\mathrm{F}}\right)(2,4)$ для лазеров с эффективной глубиной квантовых ям $q \varphi_{b n}=130(1,2)$ и $180 \mathrm{meV}(3,4)$.

слоев $\sim 5 \cdot 10^{15} \mathrm{~cm}^{-3}$ рассчитанное по формуле (2) значение параметра $\Theta=2.37$.

Для расчета токовой зависимости двумерной концентрации дырок в квантовой яме была получена и использовалась аналитическая зависимость

$$
P^{\mathrm{QW}}=P_{V}^{2 \mathrm{D}} \exp \left\{\ln P_{t h}^{\mathrm{QW}} / P_{V}^{2 \mathrm{D}}+\Theta /(\Theta+1) \ln \left(\Theta /(\Theta+1) J / J_{0}+1\right)\right\},
$$

где $P_{V}^{2 \mathrm{D}}$ - двумерная эффективная плотность состояний в валентной зоне квантово-размерной активной области, $P_{t h}^{\mathrm{QW}}-$ двумерная концентрация дырок на пороге лазерной генерации. На пороге лазерной генерации значение двумерной концентрации дырок соответствует двумерной концентрации электронов в квантовой яме, поэтому значение $P_{t h}^{\mathrm{QW}}$ с учетом данных работы [6] принималось равным $1.6 \cdot 10^{12} \mathrm{~cm}^{-2}$.

На рис. 2 приведены результаты численного моделирования токовой зависимости двумерной концентрации дырок в квантовой яме и положения уровня Ферми относительно дна валентной зоны квантовой ямы. В импульсных режимах диапазон изменения плотности тока накачки расширен до $100 \mathrm{kA} / \mathrm{cm}^{2}$. С ростом плотности тока накачки 


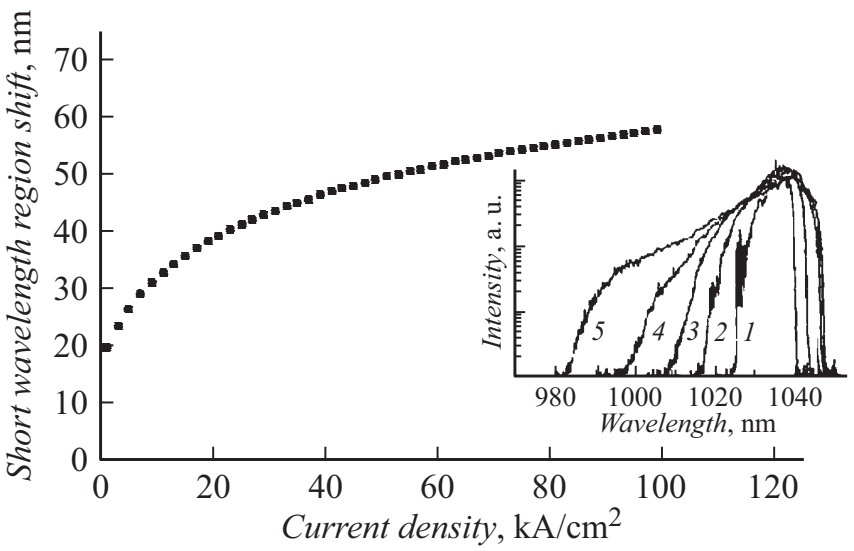

Рис. 3. Результаты численного моделирования токовой зависимости сдвига в коротковолновую область спектра излучения для лазера с эффективной глубиной квантовой ямы $q \varphi_{b n}=180 \mathrm{meV}$. На вставке - экспериментальные спектры генерации лазерного диода с соответствующей глубиной квантовой ямы [2] при плотностях тока в импульсном режиме накачки, равных 13 (1), $40(2), 67(3), 73(4)$ и $80 \mathrm{kA} / \mathrm{cm}^{2}(5)$.

двумерная концентрация дырок в квантовой яме увеличивается от порогового значения до $4.5 \cdot 10^{12}$ и $1.2 \cdot 10^{13} \mathrm{~cm}^{-2}$ соответственно для двух групп лазеров с эффективной глубиной квантовой ямы 130 и $180 \mathrm{meV}$. Столь большое различие в абсолютных значениях слоевой концентрации обусловлено различием электрической эффективности изотипных гетеропереходов на интерфейсной границе волноводных и активной областей. С ростом слоевой концентрации дырок в квантовой яме происходит смещение квазиуровня Ферми в глубь валентной зоны активной области (кривые 2, 4). Положение квазиуровня Ферми определяет условие стимулированной рекомбинации электронов с уровня размерного квантования в зоне проводимости и дырок с подзоны уровней размерного квантования валентной зоны. Предложенная модель дала возможность оценить уширение спектральных характеристик лазеров в коротковолновую область, вычисляя заполняемость дырками подзоны размерного квантования валентной зоны. Рассчитанная токовая зависимость коротковолнового сдвига представлена на рис. 3. Коротко-

4* Письма в ЖТФ, 2018, том 44, вып. 11 
волновая граница спектра генерации смещается с ростом тока накачки. При токе накачки $80-100 \mathrm{kA} / \mathrm{cm}^{2}$ ширина спектра генерации достигает $60 \mathrm{~nm}$. На вставке к рис. 3 приведены экспериментальные спектры генерации лазерного диода с соответствующей глубиной квантовой ямы [2] при различных плотностях тока в импульсном режиме накачки. Получено соответствие расчетных и экспериментальных спектральных характеристик. Численное моделирование было выполнено для лазеров спектрального диапазона 1.0-1.1 $\mu \mathrm{m}$ с асимметричным положением активной области в сверхшироком волноводе. Проведенные оценки показывают существенное влияние на описанные зависимости параметра $\Theta$. Для лазеров с $\Theta<2$ могут наблюдаться более слабые токовые зависимости коротковолнового сдвига спектра излучения. Таким образом, предложенная физическая модель определяет новое направление исследований оптической эффективности и спектральных характеристик мощных лазеров при высоких уровнях накачки.

\section{Список литературы}

[1] Слипченко С.О., Винокуров Д.А., Пихтин Н.А., Соколова З.Н., Станкевич А.Л., Тарасов И.С., Алфёров Ж.И. // ФТП. 2004. Т. 38. В. 12. С. 14771486.

[2] Слипченко С.О., Соколова З.Н., Пихтин Н.А., Борщев К.С., Винокуров Д.А., Тарасов И.С. // ФТП. 2006. Т. 40. В. 8. С. 1017-1023.

[3] Воробьев Л.Е., Зерова В.Л., Борщёв К.С., Соколова З.Н., Тарасов И.С., Belenky G. // ФТП. 2008. Т. 42. В. 6. С. 753-761.

[4] Веселов Д.А., Шашкин И.С., Пихтин Н.А., Слипченко С.О., Соколова З.Н., Тарасов И.С. // Письма в ЖТФ. 2015. Т. 41. В. 6. С. 10-16.

[5] С. Зи. Физика полупроводниковых приборов. М.: Мир, 1984. Т. 1. С. 135-136.

[6] Соколова 3.Н., Бахвалов К.В., Лютеикий А.В., Пихтин Н.А., Тарасов И.С., Асрян Л.В. // ФТП. 2016. Т. 50. В. 5. С. 679-682. 